\title{
Impact of Oxaliplatin-Induced Neuropathy on Subsequent Paclitaxel for Advanced Gastric Cancer
}

\author{
Jun Sato, Satoru Iwasa, Yoshitaka Honma, Atsuo Takashima, Natsuko Okita, Ken Kato, \\ Tetsuya Hamaguchi, Yasuhide Yamada, Narikazu Boku
}

Gastrointestinal Medical Oncology Division, National Cancer Center Hospital, Tokyo, Japan

Email: junsato2@ncc.go.jp

How to cite this paper: Sato, J., Iwasa, S., Honma, Y., Takashima, A., Okita, N., Kato, K., Hamaguchi, T., Yamada, Y. and Boku, N. (2020) Impact of Oxaliplatin-Induced Neuropathy on Subsequent Paclitaxel for Advanced Gastric Cancer. International Journal of Clinical Medicine, 11, 526-537. https://doi.org/10.4236/ijcm.2020.119045

Received: August 10, 2020

Accepted: September 14, 2020

Published: September 17, 2020

Copyright (c) 2020 by author(s) and Scientific Research Publishing Inc. This work is licensed under the Creative Commons Attribution International License (CC BY 4.0).

http://creativecommons.org/licenses/by/4.0/

\begin{abstract}
Purpose: Several studies have shown that fluoropyrimidine plus oxaliplatin (SOX) is non-inferior to fluoropyrimidine plus cisplatin as first-line chemotherapy for advanced gastric cancer. We investigated retrospectively the choice of second-line regimen, along with the proportion and feasibility of paclitaxel-containing regimen, in the subsequent treatment of patients with advanced gastric cancer treated with SOX as first-line chemotherapy. Materials and Methods: We retrospectively analyzed the impact of oxaliplatin-induced neuropathy on both the choice of subsequent regimens and feasibility of subsequent chemotherapy with paclitaxel, focusing on patients with advanced gastric cancer who received S-1 plus oxaliplatin as first-line chemotherapy. Results: Twenty-seven from a total of 31 patients enrolled into the phase 2 and phase 3 study assessing S-1 plus oxaliplatin were analyzed (4 patients were deemed ineligible). Among 24 patients that had received second-line treatment, paclitaxel was not selected in 2 patients due to oxaliplatin-induced neuropathy. Paclitaxel was selected as second-line chemotherapy in 16 patients, as third-line chemotherapy in 6 patients and fourth-line chemotherapy in one patient. Severity of sensory neuropathy was grade $0 / 1 / 2 / 3$ in $11 / 10 / 2 / 0$ patients, respectively, immediately before treatment with paclitaxel, while the worst toxicity profile during paclitaxel treatment was grade 0/1/2/3 in 7/13/1/2 patients, respectively. Although there were no patients requiring dose reductions of paclitaxel due to neuropathy, 2 patients discontinued paclitaxel use due to grade 3 sensory neuropathy after 4 or 8 administrations of paclitaxel. Conclusion: Oxaliplatin-induced neuropathy during first-line chemotherapy may affect the choice and feasibility of subsequent chemotherapy with paclitaxel in advanced gastric cancer patients.
\end{abstract}




\section{Keywords}

Gastric Cancer, Neuropathy, Oxaliplatin, Paclitaxel

\section{Introduction}

Gastric cancer is one of the major causes of death and the second leading cause of cancer death in the world [1]. Despite remarkable improvement in treatment options, there are approximately 50,000 deaths per year from gastric cancer in Japan [2]. Most patients with gastric cancer are found to have advanced disease, with few patients having opportunities for surgery at time of diagnosis. Palliative systemic chemotherapy of advanced gastric cancer has been proven to improve survival and quality of life, compared to best supportive care [3] [4] [5]. Combination chemotherapy as first-line treatment provides better survival and quality of life than single agent chemotherapy, and it is accepted as the standard of care [6] [7]. Doublet combination chemotherapy with S-1 plus cisplatin has been commonly used in patients with advanced gastric cancer as first-line chemotherapy in Japan [8]. Yamada et al. reported that S-1 plus oxaliplatin (SOX) was non-inferior to S-1 plus cisplatin in terms of effect on progression-free survival [9]. Other studies have also reported that oxaliplatin-containing regimens for advanced gastric cancer as first-line chemotherapy are feasible and effective [10] [11] [12].

One of the major causes for dose reduction or treatment discontinuation with oxaliplatin-containing regimen is neuropathy. Among patients that have received oxaliplatin-containing regimen, grade 3 neuropathy has been observed to be manifested in $12.4 \%-18.2 \%$ patients [13] [14]. A recent phase 3 study using SOX in patients with advanced gastric cancer reported that the incidence of neuropathy was $85.5 \%$ for all grades and $4.7 \%$ for grade 3 [9]. Moreover, chronic oxaliplatin-induced neuropathy has been shown to persist in about $60 \%$ of patients even after discontinuation [15].

Paclitaxel is recognized as one of the most effective antitumor agents for gastric cancer and has been proven to mediate a survival benefit as second-line chemotherapy [16] [17]. A number of patients receive paclitaxel in the subsequent lines of chemotherapy after oxaliplatin-containing regimen. However, similar to oxaliplatin-containing regimen, neuropathy occurs frequently and causes treatment interruption in 5\% - 35\% of patients during the use of paclitaxel [15] [18] [19]. It has been previously reported that risk factors for taxane-induced neurotoxicity are preexisting neuropathy and treatment with other neurotoxic agents [19] [20] [21]. Considering the poor prognosis of patients with advanced gastric cancer, the choices of chemotherapy should be based not only on efficacy but also on toxicity. It is anticipated that persistent neuropathy after prior oxaliplatin use may influence the feasibility of subsequent chemotherapy with paclitaxel, as well as the efficacy thereof. 
However, there are only a few reports regarding the influence of toxicity from first-line chemotherapy on the choice and feasibility of the second-line chemotherapy. We investigated retrospectively the choice of second-line regimen, along with the proportion and feasibility of paclitaxel-containing regimen, in the subsequent treatment of patients with advanced gastric cancer treated with SOX as first-line chemotherapy.

\section{Materials and Methods}

\section{Patients}

The source of this study was 31 patients with unresectable or recurrent gastric cancer treated with SOX as first-line chemotherapy who participated in clinical trials paclitaxel after SOX at the National Cancer Center Hospital (NCCH), Japan, between 2007 and 2015. We retrospectively investigated the medical records of the patients. S-1 was given orally twice daily for the first 2 weeks of a 3-week cycle and the dose was $80 \mathrm{mg} /$ day for body surface area (BSA) $<1.25 \mathrm{~m}^{2}, 100$ $\mathrm{mg} /$ day for BSA $\geq 1.25 \mathrm{~m}^{2}$ to $<1.5 \mathrm{~m}^{2}$, and $120 \mathrm{mg} /$ day for BSA $\geq 1.5 \mathrm{~m}^{2}$. Oxaliplatin at $100 \mathrm{mg} / \mathrm{m}^{2}$ was infused for 2 hours intravenously on day 1 of each cycle [9] [22].

\section{Subsequent paclitaxel therapy}

Paclitaxel at $80 \mathrm{mg} / \mathrm{m}^{2}$ was administered intravenously over one hour on days 1,8 , and 15, every 4 weeks. Treatment was continued until disease progression, the occurrence of unacceptable toxicities, or the patient's refusal of continued treatment. Weekly administration was skipped if the neutrophil count was $<1000 / \mathrm{mm}^{3}$, the platelet count was $<75,000 / \mathrm{mm}^{3}$, or if intolerable grade 2 or more non-hematological toxicities were observed on the planned treatment day. Dose of paclitaxel was reduced to $60 \mathrm{mg} / \mathrm{m}^{2}$ when the neutrophil count was $<500 / \mathrm{mm}^{3}$, the platelet count $<25,000 / \mathrm{mm}^{3}$, or $\geq$ grade 3 non-hematological toxicity was observed. Administration was discontinued when further dose reduction was required.

\section{Evaluation and statistical analysis}

Information on patient demographics, reasons for discontinuance of first-line chemotherapy, treatment choice, and severity of neuropathy immediately before and during paclitaxel use, along with information on other adverse events, dose reduction and treatment discontinuation, were retrospectively collected by reviewing the medical records. Adverse events were evaluated according to the Common Terminology Criteria for Adverse Events, version 4.0. Tumor assessment was usually performed every 6 to 8 weeks by computed tomography. Objective responses were calculated based on the best response according to the Response Evaluation Criteria in Solid Tumors (RECIST) ver 1.1. Progression-free survival (PFS) was defined from the date of initial treatment to the date of disease progression or death, whichever came first. If a patient had not progressed or died, PFS was censored at the time of the last follow-up. Survival was estimated by the Kaplan-Meier method. The association with neuropathy due to 
SOX and paclitaxel administration were analyzed with the Chi-square test or Fisher's exact test. All statistical analyses were performed using JMP ${ }^{\circledR} 11$ (SAS Institute Inc., Cary, NC, USA).

\section{Results}

\section{Patient characteristics}

The subjects of this study were 31 patients with advanced gastric cancer, of whom 21 patients were assigned to SOX in a phase 3 study and 10 patients were enrolled in a phase 2 study of SOX (Figure 1). One patient who had received methotrexate for rheumatoid arthritis was excluded in accordance with the clinical trial protocol, and 3 patients did not receive any treatment after SOX (treatment-related death during SOX in 1 patient, complete response in 1 and complete resection in 1). Therefore, 27 patients were analyzed in this study. Patient characteristics of this cohort are shown in Table 1. Reasons for treatment discontinuation of first-line SOX were progressive disease in 21 patients, adverse events in 5 (hematological toxicities in 3, pulmonary embolism in 1, and liver dysfunction in 1) and a patient's refusal for continuance of treatment in 1 . The median cumulative oxaliplatin dose was $650 \mathrm{mg} / \mathrm{m}^{2}$ (range, $100-1375 \mathrm{mg} / \mathrm{m}^{2}$ ). Thirteen patients had grade 0 neuropathy, while 10 had grade 1 and 4 had grade 2 at the time of discontinuation of SOX.

\section{Second-line chemotherapy after failure of SOX}

Among 27 patients who discontinued chemotherapy with SOX due to disease progression and adverse events, 24 patients received second-line chemotherapy, 2 patients received best supportive care, and one patient stopped hospital visits after SOX therapy. Among 24 patients that received second-line chemotherapy, 2 patients did not select paclitaxel due to grade 2 oxaliplatin-induced neuropathy; one patient received docetaxel, and the other one received irinotecan. The association between neuropathy grade after SOX and subsequent chemotherapy is shown in Figure 2. The choice of second-line paclitaxel was $82 \%(n=9 / 11)$ in the grade 0 neuropathy group and $54 \%(n=7 / 13)$ in the grade 1 or 2 neuropathy

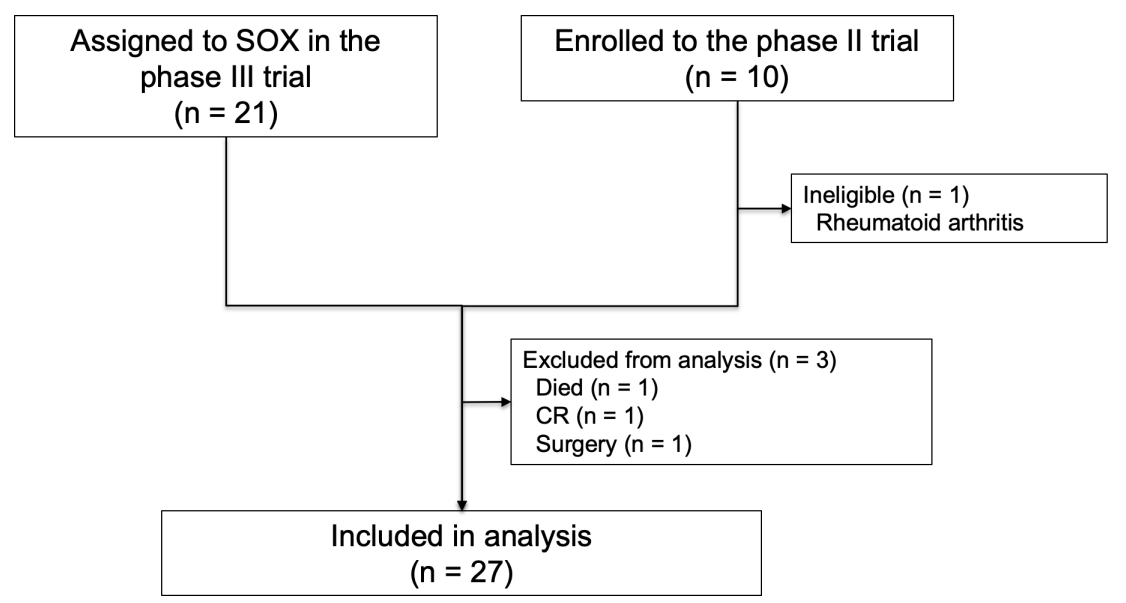

Figure 1. CONSORT diagram. 
Table 1. Patient characteristics.

\begin{tabular}{|c|c|}
\hline Characteristics & $\mathrm{n}$ \\
\hline \multicolumn{2}{|l|}{ Gender } \\
\hline Male & 22 \\
\hline Female & 5 \\
\hline \multicolumn{2}{|l|}{ PS } \\
\hline 0 & 14 \\
\hline 1 & 13 \\
\hline \multicolumn{2}{|l|}{ Histological type } \\
\hline Intestinal & 11 \\
\hline Diffuse & 15 \\
\hline Unknown & 1 \\
\hline \multicolumn{2}{|l|}{ Number of metastatic sites } \\
\hline 1 & 3 \\
\hline 2 & 16 \\
\hline$\geq 3$ & 8 \\
\hline \multicolumn{2}{|l|}{ Disease status } \\
\hline Stage IV & 20 \\
\hline Recurrence & 7 \\
\hline \multicolumn{2}{|l|}{ HER2 status } \\
\hline Positive & 2 \\
\hline Negative & 12 \\
\hline Unknown & 13 \\
\hline \multicolumn{2}{|l|}{ Cumulative oxaliplatin dose } \\
\hline Median (range), $\mathrm{mg} / \mathrm{m}^{2}$ & $650(100-1375)$ \\
\hline
\end{tabular}

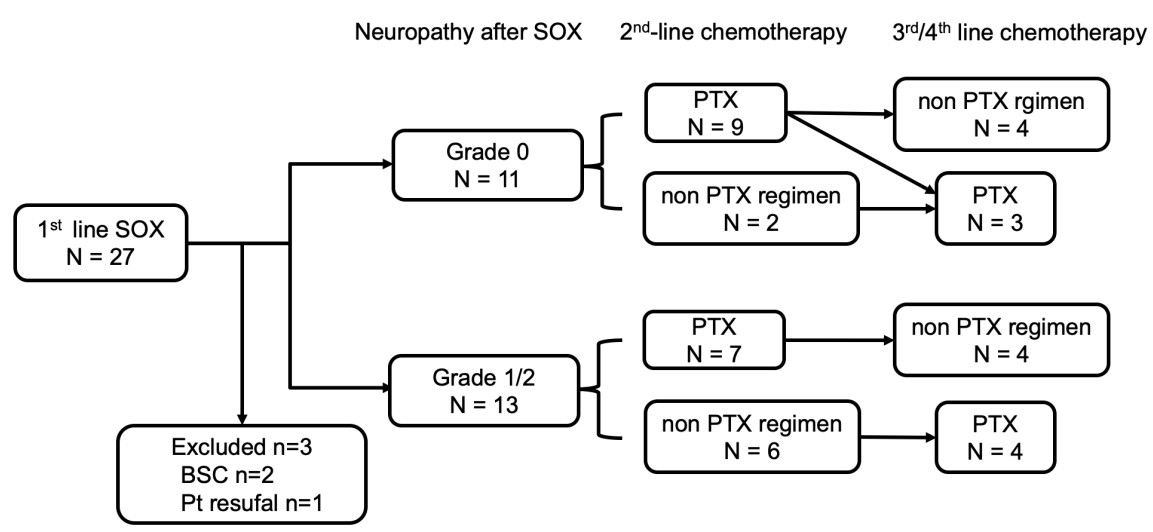

Figure 2. Association between neuropathy grade after S-1 plus oxaliplatin and subsequent chemotherapy.

group, with no significant difference found with the Fisher's exact test $(p=0.21)$. While most patients (85\%) received paclitaxel as the subsequent chemotherapy after the first-line SOX treatment, two patients with oxaliplatin-induced grade 1 
or 2 neuropathy did not receive paclitaxel at all during the whole treatment line.

\section{Safety of subsequent paclitaxel after SOX}

Among 24 patients that received subsequent chemotherapy after failure of SOX, paclitaxel was administered in 23 patients (96\%): second-line chemotherapy was given in 16 patients, third-line in 6 patients, and fourth-line in one patient. Neuropathy grade before and after administration of paclitaxel is shown in Table 2. Although there were no patients that required dose reductions of paclitaxel due to neuropathy, two patients discontinued paclitaxel due to grade 3 sensory neuropathy: pre-existing grade 2 oxaliplatin-induced neuropathy in one patient worsened to grade 3 after 4 times of second-line paclitaxel, and in the remaining one patient pre-existing grade 1 oxaliplatin-induced neuropathy worsened to grade 3 after 8 times of third-line paclitaxel. The number of administrations of paclitaxel and grades of neuropathy in second-line and third-line chemotherapy are shown in Figure 3 and Figure 4 . X-axis shows the number of cycles of paclitaxel administration and $\mathrm{Y}$-axis represents patients' numbers in each figure. The median number of administrations was 5.5 times (Table 3). Relative

Table 2. Association between neuropathy and paclitaxel.

\begin{tabular}{|c|c|c|c|c|c|c|}
\hline \multirow{2}{*}{ Neuropathy } & \multicolumn{2}{|c|}{$\begin{array}{l}\text { 2nd-line PTX } \\
\qquad \mathrm{n}=16\end{array}$} & \multicolumn{2}{|c|}{$\begin{array}{c}\text { 3rd-line PTX } \\
\qquad \mathrm{n}=6\end{array}$} & \multicolumn{2}{|c|}{$\begin{array}{l}\text { 4th-line PTX } \\
\qquad \mathrm{n}=1\end{array}$} \\
\hline & before & after & before & after & before & after \\
\hline Grade 0 & 9 & 5 & 2 & 2 & 0 & 0 \\
\hline Grade 1 & 6 & 10 & 3 & 3 & 1 & 1 \\
\hline Grade 2 & 1 & 0 & 1 & 0 & 0 & 0 \\
\hline Grade 3 & 0 & 1 & 0 & 1 & 0 & 0 \\
\hline
\end{tabular}

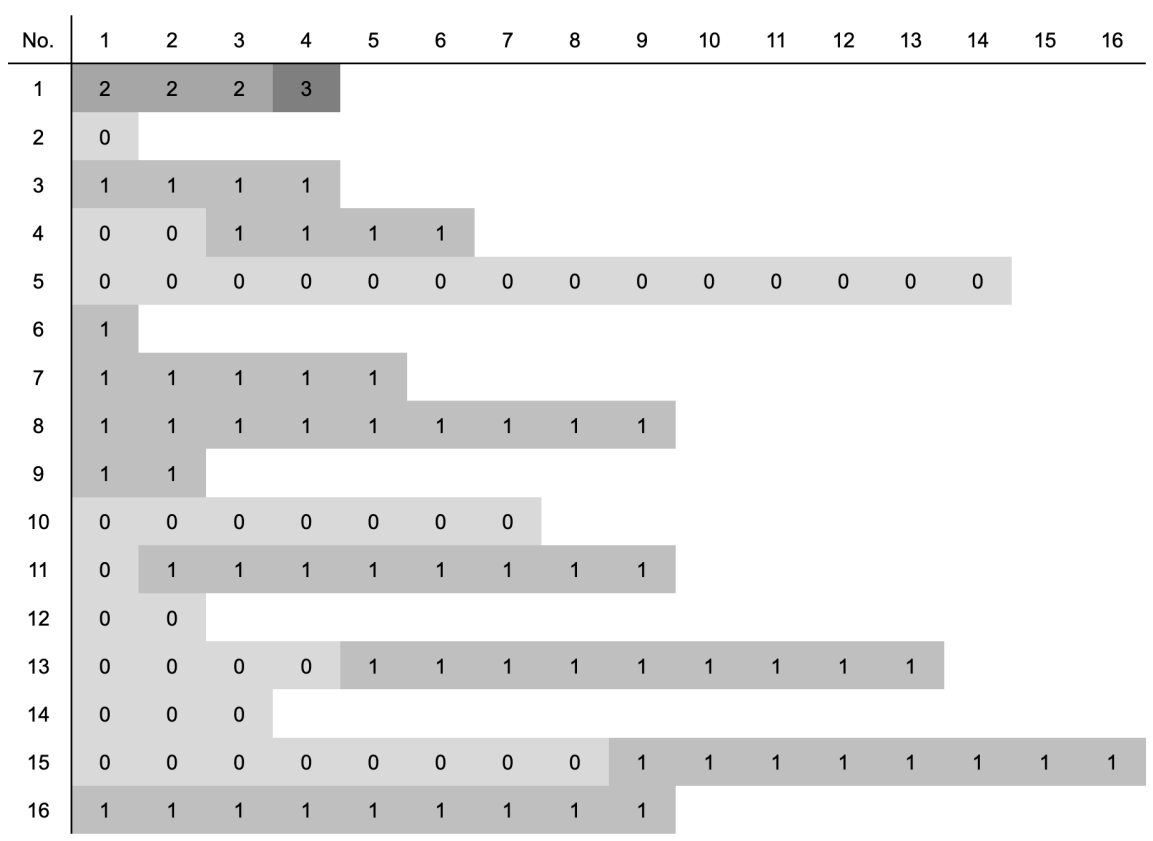

Figure 3. Neuropathy grade after second-line paclitaxel. 


\begin{tabular}{c|cccccccccccccc} 
No. & 1 & 2 & 3 & 4 & 5 & 6 & 7 & 8 & 9 & 10 & 11 & 12 & 13 & 14 \\
\hline 1 & 2 & 1 & 2 & 2 & 1 & 1 & 1 & 2 & 1 & 1 & 2 & 1 & 1 & 1 \\
2 & 1 & 1 & 1 & 1 & 1 & 1 & 1 & 3 & & & & & \\
3 & 1 & 1 & 1 & 1 & 1 & 1 & 1 & 1 & 1 & 1 & 1 & 1 & 1 \\
4 & 0 & 0 & 0 & & & & & & & & & & \\
5 & 1 & 1 & 1 & 1 & 1 & 1 & 1 & & & & & & \\
6 & 0 & 0 & 0 & & & & & & & & & &
\end{tabular}

Figure 4. Neuropathy grade after third-line paclitaxel.

Table 3. Second-line paclitaxel and neuropathy grade.

\begin{tabular}{ccccc}
\hline \multirow{2}{*}{ Pt. no } & $\begin{array}{c}\text { Cumulative oxaliplatin } \\
\text { dose }\left(\mathrm{mg} / \mathrm{m}^{2}\right)\end{array}$ & $\begin{array}{c}\text { Nefore PTX } \\
\text { administration }\end{array}$ & $\begin{array}{c}\text { After PTX } \\
\text { administration }\end{array}$ & $\begin{array}{c}\text { Total administration } \\
\text { number of PTX }\end{array}$ \\
\hline 1 & 700 & 2 & 3 & 4 \\
2 & 500 & 0 & 0 & 1 \\
3 & 900 & 1 & 1 & 4 \\
4 & 400 & 0 & 1 & 6 \\
5 & 900 & 0 & 0 & 14 \\
6 & 800 & 1 & 1 & 1 \\
7 & 1375 & 1 & 1 & 5 \\
8 & 700 & 1 & 1 & 2 \\
9 & 600 & 1 & 1 & 7 \\
10 & 100 & 0 & 0 & 9 \\
11 & 628 & 0 & 1 & 2 \\
12 & 500 & 0 & 0 & 13 \\
13 & 1000 & 0 & 1 & 3 \\
14 & 100 & 0 & 0 & 16 \\
15 & 300 & 0 & 1 & 9 \\
16 & 600 & & 1 & 9 \\
\hline
\end{tabular}

dose intensity was calculated as $52.2 \mathrm{mg} / \mathrm{m}^{2} /$ week, which corresponded to $87 \%$ of the planned dose. Neuropathy grade before second-line paclitaxel had few influence on dose intensity and median number of administrations (Table 4). Among 16 patients who received paclitaxel as second-line chemotherapy, 3 patients (19\%) discontinued treatment due to adverse events; one patient had grade 3 sensory neuropathy, another developed pneumonitis related to paclitaxel and the other had severe lung infection that was unlikely to be related to paclitaxel.

\section{Efficacy of subsequent paclitaxel}

With a median follow-up of 13.8 months (range, 2 - 31), one patient was lost to follow-up. Among 16 patients that received second-line paclitaxel, 11 patients had measurable lesions of whom two (18\%) experienced a partial response, while no patients experienced a complete response. The median PFS in patients receiving second-line paclitaxel was 2.7 months (95\% CI, 1.6 - 4.9) (Figure 5). 
Table 4. The influence of neuropathy grade before second-line paclitaxel on dose intensity.

\begin{tabular}{cccc}
\hline $\begin{array}{c}\text { Neuropathy before } \\
\text { PTX administration }\end{array}$ & Number of patients & $\begin{array}{c}\text { Median PTX dose intensity } \\
\left(\mathrm{mg} / \mathrm{m}^{2} / \text { week }\right)\end{array}$ & $\begin{array}{c}\text { Median administration } \\
\text { number of PTX }\end{array}$ \\
\hline Grade 0 & 7 & 52.4 & 7 \\
Grade 1/2 & 9 & 50.4 & 4 \\
\hline
\end{tabular}

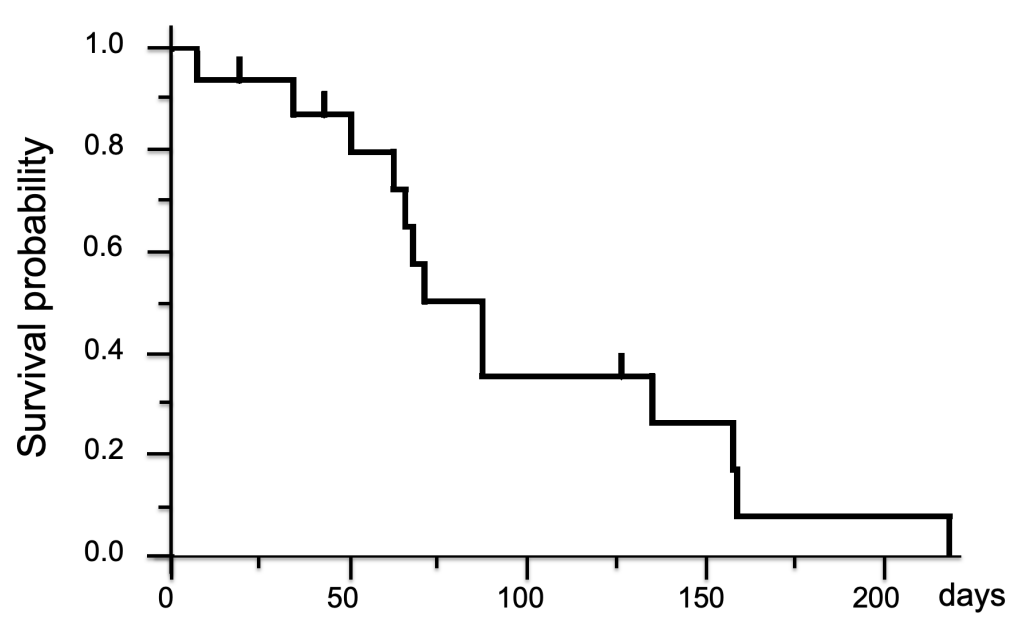

Figure 5. Kaplan-Meier curve of progression-free survival in the case of second-line paclitaxel.

\section{Discussion}

This study investigated the impact oxaliplatin-induced neuropathy on subsequent chemotherapy and the tolerability of weekly paclitaxel in patients with advanced gastric cancer treated with SOX. We revealed that paclitaxel-contaning regimens could be selected after SOX despite neurotoxicity of oxaliplatin.

In a pivotal phase III study (G-SOX trial), taxanes-containing regimens was selected as a second-line chemotherapy in $131(50.2 \%)$ out of 261 patients assigned to the SOX arm and in 102 (37.9\%) out of 269 patients assigned to the S-1 plus cisplatin (CS) arm. In our study, 16 (67\%) out of 24 patients received second-line paclitaxel after failure of SOX. Two patients (8\%) did not receive weekly paclitaxel because of oxaliplatin-induced neuropathy in our study. Oxaliplatin-induced neuropathy may impact the choice of subsequent chemotherapy with paclitaxel in patients with advanced gastric cancer, although the reasons for choice of second-line chemotherapy remains to be investigated, with a future clinical trial comparing the use of CS and SOX in this setting being merited.

The median number of second-line weekly paclitaxel administrations was 5.5 times in our study. Relative dose intensity was calculated as $52.2 \mathrm{mg} / \mathrm{m}^{2} /$ week, which corresponded to $87 \%$ of the planned dose. These results were similar to those of a previous phase III study (WJOG4007). Hironaka et al. reported that the median number of second-line weekly paclitaxel was 6 (range, 1 - 44) and the dose intensity was calculated as $55 \mathrm{mg} / \mathrm{m}^{2}$ per week (which corresponded to $92 \%$ of the planned dose) [23]. On the other hand, the discontinuation of weekly pac- 
litaxel as second-line chemotherapy in our study (19\%) was higher compared to that observed in the WJOG4007 study (6\%). First-line oxaliplatin-based chemotherapy might have an influence on the feasibility of weekly paclitaxel as second-line treatment, when comparing the rate of discontinuation observed in previous studies with our data. However, in respect to the dose intensity levels and median number of administrations described above, in our study, the feasibility of paclitaxel was not inferior to that observed in previous studies.

It is important to note the limitations of the present study. Firstly, the sample size was small as the use of oxaliplatin for the treatment of gastric cancer was not reimbursed until September 2014 in Japan. Accordingly, a large observational study is now needed to clarify the impact of oxaliplatin-induced neuropathy on subsequent chemotherapy and the tolerability of weekly paclitaxel in patients with advanced gastric cancer treated with SOX. Secondly, although paclitaxel, docetaxel or irinotecan could be selected as a standard second-line chemotherapy at that time, a new standard second-line chemotherapy with paclitaxel and ramucirumab had emerged. Physicians must face this decision regarding selection or not of paclitaxel after failure of oxaliplatin-based chemotherapy. Therefore, physicians may possibly select paclitaxel plus ramucirumab, even if the patient has oxaliplatin-induced neuropathy.

\section{Conclusion}

Weekly paclitaxel seems to be feasible in patients with advanced gastric cancer treated with SOX as first-line chemotherapy. However, its use may have influence on the selection of agents used as second-line chemotherapy.

\section{Acknowledgements}

This research did not receive any specific grant from any funding agency in the public, commercial or not-for-profit sector.

\section{Availability of Data and Materials}

The data that support the findings of this study are available from the corresponding author upon reasonable request.

\section{Authors' Contributions}

SI designed the study. JS contributed to statistical analysis and wrote the manuscript. NB supported the statistical analysis and manuscript. All authors have read and approved the final manuscript.

\section{Ethics Approval and Consent to Participate}

This retrospective study was conducted under an approval by the institutional review board according to the Japanese ethical guidelines for epidemiologic research. Informed consent or broad consent for it was obtained from all patients for being included in the study. 


\section{Conflicts of Interest}

Jun Sato has no conflict of interest; Satoru Iwasa has no conflict of interest; Yoshitaka Honma has no conflict of interest; Atsuo Takashima has no conflict of interest; Natsuko Okita has no conflict of interest; Ken Kato has no conflict of interest; Tetsuya Hamaguchi has no conflict of interest; Yasuhide Yamada has no conflict of interest; Narikazu Boku received lecture fees from Eli Lilly Japan, Taiho, Yakult, Shionogi, MerkSerono, Ono and research funding from Taiho and Ono.

\section{References}

[1] Kelley, J.R. and Duggan, J.M. (2003) Gastric Cancer Epidemiology and Risk Factors. Journal of Clinical Epidemiology, 56, 1-9. https://doi.org/10.1016/S0895-4356(02)00534-6

[2] Health and Welfare Statistics Association (1999) The Movement of Population. $J$ Health Welfare Stat, 46, 41-72.

[3] Moon, Y.W., Rha, S.Y., Jeung, H.C., Kim, C., Hong, M.H., Chang, H., Roh, J.K., Noh, S.H., Kim, B.S. and Chung, H.C. (2010) Outcomes of Multiple Salvage Chemotherapy for Advanced Gastric Cancer: Implications for Clinical Practice and Trial Design. Cancer Chemotherapy and Pharmacology, 66, 797-805. https://doi.org/10.1007/s00280-010-1295-Z

[4] Farhat, F.S., Kattan, J., Chahine, G.Y., Younes, F.C., Nasr, F.L., Mroue, R.M. and Ghosn, M.G. (2010) Role of Low Dose Capecitabine Combined to Irinotecan in Advanced and Metastatic Gastric Cancer. Medical Oncology, 27, 722-727. https://doi.org/10.1007/s12032-009-9275-Z

[5] Benson, A.B. (2008) Advanced Gastric Cancer: An Update and Future Directions. Gastrointestinal Cancer. Research \& Therapy, 2, S47-S53.

[6] Kim, Y.H. (2005) Chemotherapy for Advanced Gastric Cancer: Slow but Further Progress. Cancer Research and Treatment, 37, 79-86. https://doi.org/10.4143/crt.2005.37.2.79

[7] Wagner, A.D., Grothe, W., Haerting, J., Kleber, G., Grothey, A. and Fleig, W.E. (2006) Chemotherapy in Advanced Gastric Cancer: A Systematic Review and Meta-Analysis Based on Aggregate Data. Journal of Clinical Oncology, 24, 2903-2909. https://doi.org/10.1200/JCO.2005.05.0245

[8] Koizumi, W., Narahara, H., Hara, T., Takagane, A., Akiya, T., Takagi, M., Miyashita, K., Nishizaki, T., Kobayashi, O., Takiyama, W., Toh, Y., Nagaie, T., Takagi, S., Yamamura, Y., Yanaoka, K., Orita, H. and Takeuchi, M. (2008) S-1 Plus Cisplatin versus S-1 Alone for First-Line Treatment of Advanced Gastric Cancer (SPIRITS Trial): A Phase III Trial. The Lancet Oncology, 9, 215-221. https://doi.org/10.1016/S1470-2045(08)70035-4

[9] Yamada, Y., Higuchi, K., Nishikawa, K., Gotoh, M., Fuse, N., Sugimoto, N., Nishina, T., Amagai, K., Chin, K., Niwa, Y., Tsuji, A., Imamura, H., Tsuda, M., Yasui, H., Fujii, H., Yamaguchi, K., Yasui, H., Hironaka, S., Shimada, K., Miwa, H., Hamada, C. and Hyodo, I. (2015) Phase III Study Comparing Oxaliplatin Plus S-1 with Cisplatin plus S-1 in Chemotherapy-Naïve Patients with Advanced Gastric Cancer. Annals of Oncology, 26, 141-148. https://doi.org/10.1093/annonc/mdu472

[10] Cunningham, D., Starling, N., Rao, S., Iveson, T., Nicolson, M., Coxon, F., Middleton G, Daniel, F., Oates, J. and Norman, A.R. (2008) Upper Gastrointestinal Clinical 
Studies Group of the National Cancer Research Institute of the United Kingdom. Capecitabine and Oxaliplatin for Advanced Esophagogastric Cancer. The New England Journal of Medicine, 358, 36-46. https://doi.org/10.1056/NEJMoa073149

[11] Kim, Y.S, Sym, S.J., Park, S.H., Park, I., Hong, J., Ahn, H.K., Park, J., Cho, E.K., Lee, W.K., Chung, M., Lee, J.H. and Shin, D.B. (2014) A Randomized Phase II Study of Weekly Docetaxel/Cisplatin versus Weekly Docetaxel/Oxaliplatin as First-Line Therapy for Patients with Advanced Gastric Cancer. Cancer Chemotherapy and Pharmacology, 73, 163-169. https://doi.org/10.1007/s00280-013-2334-3

[12] Al-Batran, S.E., Hartmann, J.T., Probst, S., Schmalenberg, H., Hollerbach, S., Hofheinz, R., Rethwisch, V., Seipelt G, Homann, N., Wilhelm, G., Schuch, G., Stoehlmacher, J., Derigs, H.G., Hegewisch-Becker, S., Grossmann, J., Pauligk, C., Atmaca, A., Bokemeyer, C., Knuth, A. and Jäger, E. (2008) Arbeitsgemeinschaft Internistische Onkologie. Phase III Trial in Metastatic Gastroesophageal Adenocarcinoma with Fluorouracil, Leucovorin Plus Either Oxaliplatin or Cisplatin: A Study of the Arbeitsgemeinschaft Internistische Onkologie. Journal of Clinical Oncology, 26, 1435-1442. https://doi.org/10.1200/JCO.2007.13.9378

[13] De Gramont, A., Figer, A., Seymour, M., Homerin, M., Hmissi, A., Cassidy, J., Boni, C., Cortes-Funes, H., Cervantes, A., Freyer, G., Papamichael, D., Le Bail, N., Louvet, C., Hendler, D., De Braud, F., Wilson, C., Morvan, F. and Bonetti, A. (2000) Leucovorin and Fluorouracil with or Without Oxaliplatin as First-Line Treatment in Advanced Colorectal Cancer. Journal of Clinical Oncology, 18, 2938-2947. https://doi.org/10.1200/JCO.2000.18.16.2938

[14] André, T., Boni, C., Mounedji-Boudiaf, L., Navarro, M., Tabernero, J., Hickish, T., Topham, C., Zaninelli, M., Clingan, P., Bridgewater, J., Tabah-Fisch, I., De Gramont, A. and for the Multicenter International Study of Oxaliplatin/5-Fluorouracil/ Leucovorin in the Adjuvant Treatment of Colon Cancer (MOSAIC) Investigators. (2004) Oxaliplatin, Fluorouracil, and Leucovorin as Adjuvant Treatment for Colon Cancer. The New England Journal of Medicine, 350, 2343-2451. https://doi.org/10.1056/NEJMoa032709

[15] Park, S.B., Goldstein, D., Krishnan, A.V., Lin, C.S., Friedlander, M.L., Cassidy, J., Koltzenburg, M. and Kiernan, M.C. (2013) Chemotherapy-Induced Peripheral Neurotoxicity: A Critical Analysis. CA: A Cancer Journal for Clinicians, 63, 419-437. https://doi.org/10.3322/caac.21204

[16] Yamada, Y., Shirao, K., Ohtsu, A., Boku, N., Hyodo, I., Saitoh, H., Miyata, Y. and Taguchi, T. (2001) Phase II Trial of Paclitaxel by Three-Hour Infusion for Advanced Gastric Cancer with Short Premedication for Prophylaxis against Paclitaxel-Associated Hypersensitivity Reactions. Annals of Oncology, 12, 1133-1137.

[17] Hironaka, S., Ueda, S., Yasui, H., Nishina, T., Tsuda, M., Tsumura, T., Sugimoto, N., Shimodaira, H., Tokunaga, S., Moriwaki, T., Esaki, T., Nagase, M., Fujitani, K., Yamaguchi, K., Ura, T., Hamamoto, Y., Morita, S., Okamoto, I., Boku, N. and Hyodo, I. (2013) Randomized, Open-Label, Phase III Study Comparing Irinotecan with Paclitaxel in Patients with Advanced Gastric Cancer Without Severe Peritoneal Metastasis after Failure of Prior Combination Chemotherapy Using Fluoropyrimidine plus Platinum: WJOG 4007 Trial. Journal of Clinical Oncology, 31, 4438-4444. https://doi.org/10.1200/JCO.2012.48.5805

[18] Miltenburg, N.C. and Boogerd, W. (2014) Chemotherapy-Induced Neuropathy: A Comprehensive Survey. Cancer Treatment Reviews, 40, 872-882. https://doi.org/10.1016/j.ctrv.2014.04.004

[19] Argyriou, A.A., Kyritsis, A.P., Makatsoris, T. and Kalofonos, H.P. (2014) Chemotherapy-Induced Peripheral Neuropathy in Adults: A Comprehensive Update of the 
Literature. Cancer Management and Research, 6, 135-147. https://doi.org/10.2147/CMAR.S44261

[20] Eckhoff, L., Knoop, A.S., Jensen, M.B., Ejlertsen, B. and Ewertz, M. (2013) Risk of Docetaxel-Induced Peripheral Neuropathy among 1,725 Danish Patients with Early Stage Breast Cancer. Breast Cancer Research and Treatment, 142, 109-118. https://doi.org/10.1007/s10549-013-2728-2

[21] Schneider, B.P., Zhao, F., Wang, M., Stearns, V., Martino, S., Jones, V., Perez, E.A., Saphner, T., Wolff, A.C., Sledge Jr., G.W., Wood, W.C., Davidson, N.E. and Sparano, J.A. (2012) Neuropathy Is Not Associated with Clinical Outcomes in Patients Receiving Adjuvant Taxane-Containing Therapy for Operable Breast Cancer. Journal of Clinical Oncology, 30, 3051-3057. https://doi.org/10.1200/JCO.2011.39.8446

[22] Koizumi, W., Takiuchi, H., Yamada, Y., Boku, N., Fuse, N., Muro, K., Komatsu, Y. and Tsuburaya, A. (2010) Phase II Study of Oxaliplatin Plus S-1 as First-Line Treatment for Advanced Gastric Cancer (G-SOX Study). Annals of Oncology, 21, 1001-1005. https://doi.org/10.1093/annonc/mdp464

[23] Hironaka, S., Zenda, S., Boku, N., Fukutomi, A., Yoshino, T. and Onozawa, Y. (2006) Weekly Paclitaxel as Second-Line Chemotherapy for Advanced or Recurrent Gastric Cancer. Gastric Cancer, 9, 14-18. https://doi.org/10.1007/s10120-005-0351-6

\section{List of Abbreviations}

BSA: body surface area;

CS: S-1 plus cisplatin;

PFS: Progression-free survival;

RECIST: Response Evaluation Criteria in Solid Tumors;

SOX: S-1 plus oxaliplatin. 